\title{
Directed differentiation of postnatal hippocampal neural stem cells generates nuclear receptor related-1 protein- and tyrosine hydroxylase-expressing cells
}

\author{
YINXIU DING $^{1 *}$, ZIXIN ZHANG ${ }^{2 *}$, JIANGBO MA $^{1}$, HECHUN XIA $^{3}$, \\ YIN WANG ${ }^{1}$, YINMING LIU ${ }^{1}$, QUANRUI MA ${ }^{1}$, TAO SUN ${ }^{1}$ and JUAN LIU ${ }^{1}$ \\ ${ }^{1}$ Ningxia Key Laboratory of Cerebrocranial Diseases, Basic Medical College of Ningxia Medical University; \\ Departments of ${ }^{2}$ Radiotherapy and ${ }^{3}$ Cerebral Surgery, The General Hospital of Ningxia Medical University, \\ Yinchuan, Ningxia 750004, P.R. China
}

Received August 24, 2015; Accepted May 10, 2016

DOI: $10.3892 / \mathrm{mmr} .2016 .5489$

\begin{abstract}
Parkinson's disease (PD) is a severe neurodegenerative disorder. Although the detailed underlying molecular mechanism remains to be elucidated, the major pathological feature of PD is the loss of dopaminergic (DA) neurons of the substantia nigra. The use of donor stem cells to replace DA neurons may be a key breakthrough in the treatment of PD. In the present study, the growth kinetics of hippocampal neural stem cells (Hip-NSCs) isolated from postnatal mice and cultured in vitro were observed, specifically the generation of cells expressing DA neuronal markers nuclear receptor related-1 protein (Nurr1) and tyrosine hydroxylase (TH). It was revealed that Hip-NSCs differentiated primarily into astrocytes when cultured in serum-containing medium. However, in low serum conditions, the number of $\beta$ III tubulin-positive neurons increased markedly. The proportion of Nurrl-positive cells and TH-positive neurons, significantly increased with increasing duration of directed differentiation of Hip-NSCs ( $\mathrm{P}=0.0187$ and 0.0254 , respectively). The results of the present study reveal that Hip-NSCs may be induced to differentiate in vitro into neurons expressing Nurrl and TH, known to be critical regulators of DA neuronal fate. Additionally, their expression may be necessary to facilitate neuronal maturation in vitro. These data suggest that Hip-NSCs may serve as a
\end{abstract}

Correspondence to: Mrs. Juan Liu or Mr. Tao Sun, Ningxia Key Laboratory of Cerebrocranial Diseases, Basic Medical College of Ningxia Medical University, 1160 Shengli Street, Yinchuan, Ningxia 750004, P.R. China

E-mail: ryuken0518@163.com

E-mail: suntao@nxmu.edu.cn

*Contributed equally

Key words: primary cell culture, hippocampus, neural stem cells, neurospheres source of DA neurons for cell therapy in patients diagnosed with PD.

\section{Introduction}

Parkinson's disease (PD) is a progressively debilitating neurodegenerative disorder (1). The major pathological feature of PD is the selective degeneration and loss of dopaminergic (DA) neurons of the substantia nigra leading to a significant reduction in synthesis of extrapyramidal dopamine (2). Currently available medication only alleviates symptoms temporarily and cannot cure PD (3). It is therefore imperative to identify safe and effective methods of treating this disorder, preferably by supplementing patients with DA neurons. One approach is to investigate the dynamics of postnatal and adult neurogenesis in vivo, which if successfully manipulated may succeed in correcting the dopamine imbalance in PD patients $(4,5)$. Another approach is to generate healthy DA neurons in vitro and transplant them into the brains of PD patients to replenish the loss (6).

The multipotent neural stem cells (NSCs) identified in the adult hippocampus have the ability to proliferate and differentiate throughout the lifetime of the individual. Numerous studies have demonstrated that NSCs secrete various neurotrophic factors, neurotransmitters and enzymes (7-9). In response to molecular signals from the microenvironment, transplanted hippocampal NSCs (Hip-NSCs) differentiate into various types of neurons and glia in vivo, a property that may be recapitulated in vitro under appropriate conditions. Transplanted Hip-NSCs may not only replenish the reservoir of neurotrophic growth factors in the damaged nervous tissue, but also expand and generate lost and degenerated neurons to achieve functional recovery $(10,11)$. The multipotency of NSCs affords them a broad application in cell replacement therapy and injury repair in diseases of the central nervous system $(12,13)$.

In the present study, Hip-NSCs were isolated from postnatal mouse brains and cultured in vitro to monitor their proliferation, migration and differentiation properties. The dynamic expression of DA neuronal markers nuclear receptor 
related-1 protein (Nurr1) and tyrosine hydroxylase (TH) in the differentiated neurons was analyzed. Hip-NSCs were observed to differentiate into neurons with DA characteristics. The results of the present study provide further evidence of the merits of using Hip-NSCs as a suitable donor population for stem cell therapy in PD.

\section{Materials and methods}

Animals. All experiments were conducted with C57BL/6 mice (0-3 days old) provided by the Laboratory Animal Center of Ningxia Medical University (Yinchuan, China). Mice were housed at $24-25^{\circ} \mathrm{C}$ and $50-60 \%$ humidity on a 12 -h light/dark cycle. Food and water were provided ad libitum. All experiments were approved by the Animal Experimentation Ethics Committee of Ningxia Medical University (Yinchuan, China) and were specifically designed to minimize the number of animals used.

Hip-NSC culture. Obtained 0-3-day old C57BL/6 mice were sacrificed by drowning in ethyl alcohol for five min, and were stripped of the skin and periosteum of the head. Mice were then placed onto a 35-mm dish in $2 \mathrm{ml} \mathrm{Hank's} \mathrm{balanced} \mathrm{salt}$ solution, the cerebral cortex was stripped, the bilateral hippocampus was fully exposed and the intact hippocampal tissues were collected. Following removal of the blood vessels and fascia of the brain, dissected hippocampal tissues were finely minced and treated with 1-2 ml Accutase ${ }^{\circledR}$ (A1110501; Gibc Thermo Fisher Scientific, Inc., Waltham, MA, USA) at $37^{\circ} \mathrm{C}$ for $10 \mathrm{~min}$, followed by resuspension in 3-4 $\mathrm{ml}$ fresh medium. No additional washes or enzyme inhibitors were required. Following enzymatic digestion, the tissues were mechanically dissociated into a single cell suspension by gentle movement up and down in fresh medium using a pipette, in order to reduce cell damage and death. The cell suspension was centrifuged at $179 \mathrm{x} g$ for $5 \mathrm{~min}$ at room temperature. The supernatant was discarded, and the cell pellet resuspended and seeded at a density of $1 \times 10^{5}$ cells/tissue culture flask in 1:1 Dulbecco's modified Eagle's medium (DMEM) /F12 1:1 (11330-032; Gibc Thermo Fisher Scientific, Inc.) supplemented with $2 \%$ B-27 ${ }^{\circledR}$ (12587-010; Invitrogen; Thermo Fisher Scientific, Inc.), $20 \mathrm{ng} / \mathrm{ml}$ recombinant human epidermal growth factor (450-02; PeproTech, Inc., Rocky Hill, NJ, USA) and 20 ng/ml basic fibroblast growth factor (bFGF, 100-18B; PeproTech, Inc.). Cells were cultured in a humidified $5 \% \mathrm{CO}_{2} / 95 \%$ air incubator at $37^{\circ} \mathrm{C}$ for $5-7$ days. During this period, the cells gradually grew into floating neurospheres. They were maintained in culture with regular passaging every 5-7 days.

5-bromo-2'-deoxyuridine (BrdU) immunocytochemistry. Passage (P) 2 Hip-NSCs were treated with the thymidine analog BrdU (Sigma-Aldrich, St Louis, MO, USA) at $10 \mu \mathrm{mol} / 1$ upon reaching 50\% confluency. A total of $48 \mathrm{~h}$ later, the neurospheres derived from the Hip-NSCs were plated on polylysine-treated sterile glass coverslips and incubated at $37^{\circ} \mathrm{C}$ in $5 \% \mathrm{CO}_{2}$ for $2-4 \mathrm{~h}$. Following thorough rinsing with phosphate-buffered saline (PBS), the neurospheres were treated with $2 \mathrm{M}$ hydrochloric acid for $1 \mathrm{~h}$ at $37^{\circ} \mathrm{C}$ and boric acid buffer ( $\mathrm{pH} \mathrm{8.5)} \mathrm{for} 10 \mathrm{~min}$ at room temperature (RT). BrdU-incorporated cells were visualized by immunostaining. Briefly, cells were incubated with blocking
A

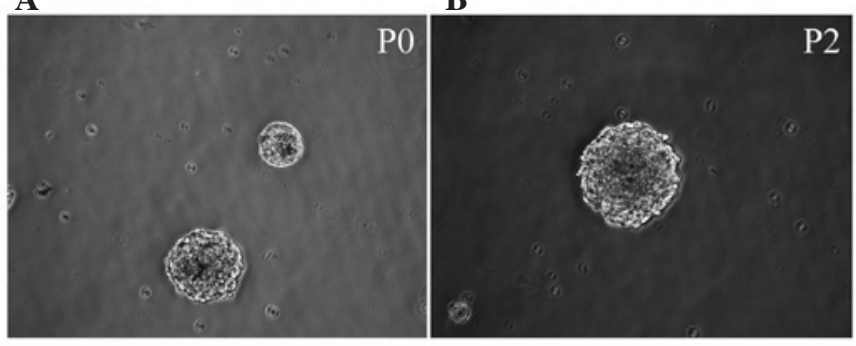

Figure 1. Neurospheres derived from the mouse hippocampus at various stages of differentiation. Cells possessed the morphological features of neurospheres (A) P0 and (B) P2. Magnification, x200. P, passage.

solution $0.3 \%$ Triton X-100 containing $1 \%$ normal donkey serum (Jackson ImmunoResearch Labortories, Inc., West Grove, PA, USA) for $30 \mathrm{~min}$. Cells were then incubated with a primary antibody mixture of mouse anti-BrdU (1:200; ab8152; Abcam, Cambridge, MA, USA) and rabbit anti-nestin (1:100; N5413; Sigma-Aldrich) for $24 \mathrm{~h}$ at $4^{\circ} \mathrm{C}$, followed by the secondary antibodies (Alexa Fluor 488-conjugated donkey anti-mouse IgG; 1:1,000; R37114; Alexa Fluor 594-conjugated donkey anti-rabbit IgG; 1:1,000; R37119; both Thermo Fisher Scientific, Inc.) for $4 \mathrm{~h}$ at RT. Finally, the immunostained Hip-NSCs were mounted onto glass slides using VECTASHIELD ${ }^{\circledR}$ antifade fluorescence mounting medium (Vector Laboratories, Inc., Burlingame, CA, USA), and observed under a fluorescence microscope.

Differentiation of Hip-NSCs. P2 Hip-NSCs were seeded onto polylysine-treated coverslips at 30-40 cells/coverslip in a 24-well plate. To induce differentiation, these cells were cultured in low-serum conditioned medium containing DMEM/F12 1:1 supplemented with $2 \%$ fetal bovine serum (26140-111, Gibc Thermo Fisher Scientific, Inc.) and 100 ng/ml FGF-8 (100-25, PeproTech, Inc.). The growth medium was replaced every 2-3 days, and immunocytochemistry and western blotting were performed following 3-7 days of differentiation.

Immunocytochemistry of differentiated Hip-NSCs. Following flattening and adhesion, Hip-NSCs and their differentiated progeny were washed in PBS 2-3 times and incubated overnight at $4^{\circ} \mathrm{C}$ with the following primary antibodies: Rabbit anti-Nurr1 (1:1,000; N4663; Sigma-Aldrich), mouse anti-TH (1:8,000; T2928; Sigma-Aldrich), mouse anti-glial fibrillary acidic protein (GFAP; 1:4,000; SAB1405864; Sigma-Aldrich), rabbit anti-GFAP (1:3,000; ab7779; Abcam), mouse anti- $\beta$-Tubulin III (Tuj1; 1:3,000; T5076; Sigma-Aldrich), rabbit anti-Tuj1 (1:3,000; SAB4300623; Sigma-Aldrich) and mouse anti-2', 3'-cyclic nucleotide 3'-phosphodiesterase (CNPas 1:500; C5922; Sigma-Aldrich). Cells were then incubated with the appropriate Alexa Fluor 488 or Alexa Fluor 555-labeled secondary antibodies (1:500; goat anti-mouse IgG; A11001; goat anti-rabbit IgG; A31629; Invitrogen; Thermo Fisher Scientific, Inc.). Nuclei were stained with Hoechst 33342 (1:500; B2261; Sigma-Aldrich). Coverslips were mounted onto slides, and observed under a fluorescence microscope.

Western blot analysis. This assay was performed as described previously (14). Hip-NSCs and their differentiated progeny were treated with radioimmunoprecipitation assay lysis buffer 

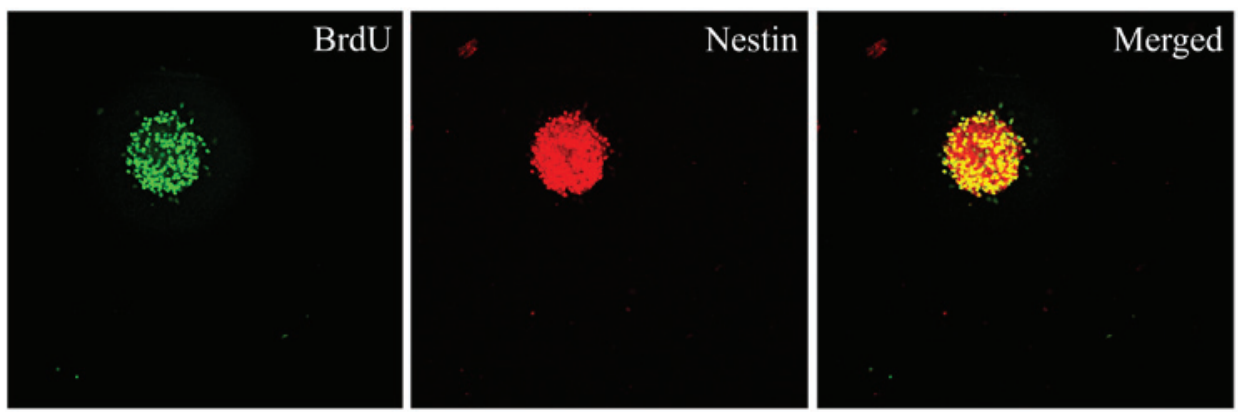

Figure 2. Immunocytochemical detection of proliferation markers in neurospheres derived from the mouse hippocampus. Neurospheres were stained for BrdU and nestin and an overlay of the two images was produced. Magnification, x200. BrdU, 5-bromo-2'-deoxyuridine.

containing $2 \%$ protease inhibitor (Boehringer Mannheim, Mannheim, Germany) for $30 \mathrm{~min}$, removed with a cell scraper (on ice), transferred to $2 \mathrm{ml}$ microcentrifuge tubes and pelleted by centrifugation at $13,314 \mathrm{x}$ g for $5-10 \mathrm{~min}$ at $4^{\circ} \mathrm{C}$. The supernatant was transferred to fresh microcentrifuge tubes and the total protein concentration was estimated using the bicinchoninic acid assay according to the manufacturer's instructions. A total of $20-30 \mu \mathrm{g}$ protein was loaded in each well of a $10 \%$ SDS-PAGE gel, separated by electrophoresis $(2 \mathrm{~h}$ at $120 \mathrm{mV}$ ) and transferred to polyvinylidene difluoride membranes (100 min at $130 \mathrm{~mA}$ ). The membranes were blocked with 5\% milk at RT for $1 \mathrm{~h}$ and incubated overnight at $4^{\circ} \mathrm{C}$ with the following primary antibodies: Rabbit anti-Nurr1 $(1: 1,000$; N4663; Sigma-Aldrich), mouse anti-TH (1:8,000; T2928; Sigma-Aldrich) and mouse anti- $\beta$-actin (1:2,000; A2228; Sigma-Aldrich). The following day the membranes were washed in Tris-buffered saline with $1 \%$ Tween 20 three times, and incubated with horseradish peroxidase HRP-conjugated secondary antibodies (goat anti-rabbit; 1:3,000; ab6721; or goat anti-mous 1:3,000; ab97023; Abcam) for $1 \mathrm{~h}$ at room temperature. The protein bands were visualized by incubating the membranes in enhanced chemiluminescence substrate solution and analyzed using ImagePro-Plus version 6.0 software (Media Cybernetics, Inc., Rockville. MD, USA). The band intensity of Nurrl and TH was normalized to $\beta$-actin.

Statistical analysis. Data were collected from triplicate samples from three independent experiments. All data are expressed as the mean \pm standard error. Statistical comparisons were performed using Student's $t$-test or one-way analysis of variance, followed by Dunnett's post-hoc test. Statistical analysis was performed using SPSS version 13.0 (SPSS, Inc., Chicago, IL, USA). $\mathrm{P}<0.05$ was considered to indicate a statistically significant difference.

\section{Results}

Morphology of Hip-NSCs. Immediately following the seeding of isolated Hip-NSCs, cells were large and rounded with strong light refraction. Very little cell debris and few adherent differentiated cells were observed under a brightfield microscope. Cellular aggregates with an orbicular morphology started to appear $36 \mathrm{~h}$ later. These resembled neurospheres and their number and size increased with time (Fig. 1A). Following five days of in vitro culture, cells were

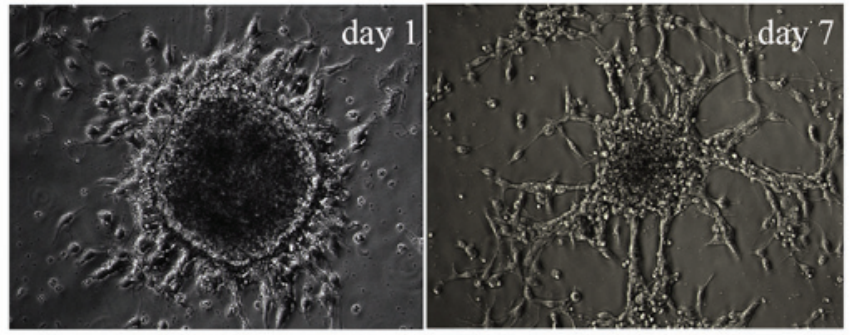

Figure 3. Neurospheres derived from the mouse hippocampus at various stages of differentiation. Cells possessed the morphological features of differentiating hippocampal neural stem cells at day 1 and day 7. Magnification, x200.

passaged by enzymatic dissociation using Accutase ${ }^{\circledR}$. Dead cells were rarely observed at this time point (Fig. 1B). During passaging, $98 \%$ of the cultured Hip-NSCs were dissociated into single cells. A total of $36 \mathrm{~h}$ subsequent to passaging, the cells reassembled into mitotically-active aggregates, exhibiting a rounded shape.

Proliferative capacity of Hip-NSCs in vitro. To determine the proliferative capacity of Hip-NSCs in vitro, neurospheres were examined by double immunofluorescence staining for incorporation of the proliferation indicator BrdU and the neural progenitor marker nestin. The results revealed that Hip-NSCs expanded rapidly in culture as visualized by the extent of BrdU incorporation and that NSCs were abundant within the neurospheres (Fig. 2).

Characteristics of differentiating Hip-NSCs. Following the second passaging of Hip-NSCs (P2), the plated cells attached to the surface completely within $4 \mathrm{~h}$, a feature characteristic of non-proliferative differentiating cells. Over time, an increasing number of cells migrated out of the neurospheres. At 12-24 h following passaging, processes began to emerge along the edge of the neurospheres (Fig. 3). During the early stages of differentiation, Hip-NSCs were arranged radially with a tendency to differentiate into astrocytes without the addition of exogenous cytokines. The majority of these glial cells stained positive for GFAP (Fig. 4A). However, when Hip-NSCs were cultured under low-serum conditions (DMEM/F12 1:1 supplemented with $2 \%$ fetal bovine serum and $100 \mathrm{ng} / \mathrm{ml} \mathrm{FGF-8)}$ there was an increase in the number of Tuj1-positive neurons 


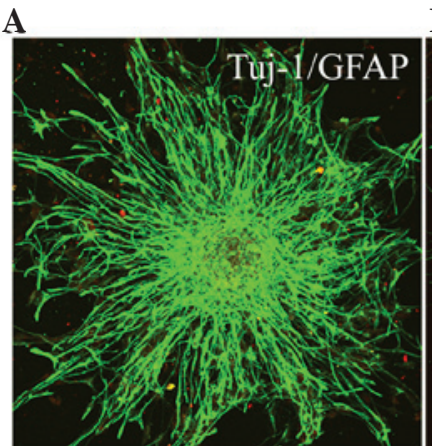

B

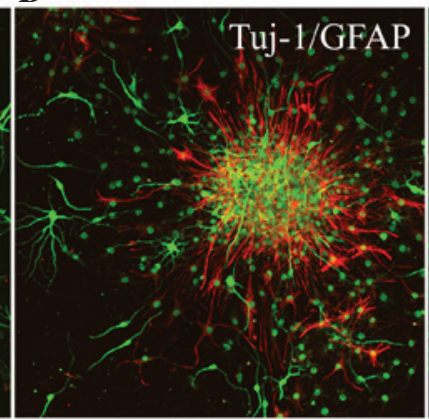

C

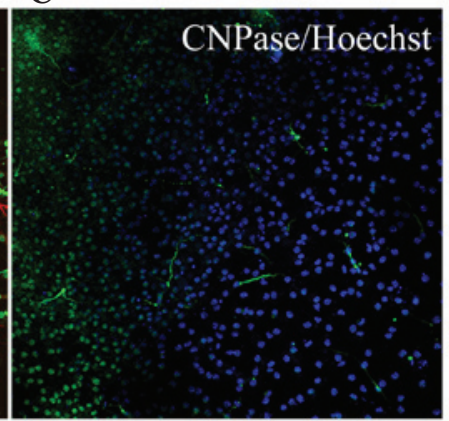

Figure 4. Immunohistochemical detection of neurons and glial cells during Hip-NSC differentiation. (A) Expression of GFAP (green) and Tuj1 (red) in differentiated Hip-NSC cultured with DMEM/F12 containing 10\% fetal bovine serum on day 3. (B) Expression of GFAP (red) and Tuj1 (green) and (C) CNPase (green) and Hoechst (blue) in differentiated Hip-NSCs cultured with DMEM/F12 supplemented with $2 \%$ fetal bovine serum and 100 ng/ml fibroblast growth factor-8 on day 3. Magnification, x200. Hip-NSC, hippocampal neural stem cell; GFAP, glial fibrillary acidic protein; Tuj1, $\beta$-Tubulin III; CNPase, 2',3'-cyclic nucleotide 3'-phosphodiesteras DMEM, Dulbecco's modified Eagle's medium.

(Fig. 4B), with fewer cells differentiating into CNPase-positive oligodendrocytes (Fig. 4C).

Expression of Nurrl and TH in differentiating Hip-NSCs. Immunofluorescent staining was performed to analyze the expression of the DA neuronal markers Nurr1 and TH at the early stages of Hip-NSC differentiation in low serum conditions. The results revealed an increasing number of Nurr1-expressing cells over time, and increased expression of TH was detected (Fig. 5A). The proportions of Nurr1-positive cells and TH-positive neurons at day 7 (39.30 \pm 3.96 and $11.9 \pm 1.68 \%$, respectively) were significantly greater than those at day $3(22.23 \pm 2.10$ and $4.63 \pm 1.25 \%$, respectively; $\mathrm{P}=0.0187$ and 0.0254 , respectively; Fig. 5B).

Quantification of Nurrl and TH expression in differentiating Hip-NSCs. To quantify and compare the levels of Nurr1 and $\mathrm{TH}$ protein expression at day 3 and 7 of differentiation a western blotting assay was performed. Nurrl and TH proteins were expressed at day $3(0.499 \pm 0.072$ and $0.212 \pm 0.031$, respectively), and their expression levels increased significantly at day $7(0.792 \pm 0.067$ and $0.473 \pm 0.072$, respectively; $\mathrm{P}=0.0409$ and 0.0292, respectively; Fig. 6).

\section{Discussion}

Advances in NSC technology have led to novel and promising therapeutic strategies for PD treatment, including transplantation of DA neurons derived from NSCs in vitro into the diseased brain, transplantation of NSCs directly into injured areas and inducing differentiation into DA neurons in vivo, and manipulation of endogenous NSCs to differentiate into DA neurons (15-17). Endogenous NSCs may thus serve as the ideal donor for cell transplantation therapy $(17,18)$. However, various studies have demonstrated that, in vitro, NSCs have an increased tendency to differentiate into glial cells than neurons, particularly DA neurons $(19,20)$. The inability to generate large numbers of DA neurons in vitro poses a major obstacle for the clinical application of NSCs in a transplantation-based treatment of PD. Therefore, there is an urgent need to identify the molecular cues and the ideal microenvironment that would facilitate this process.
Various studies have demonstrated that neurotrophic factors are important in the regulation of neuron survival, axonal maturation and neuronal differentiation during the development of the nervous system $(21,22)$. Growth factors cerebral dopamine neurotrophic factor and Parkinson disease protein 7 protect cholinergic and DA neurons against injury $(23,24)$ and additional investigation of age-associated diseases has determined that expression levels of neurotrophic factors are reduced in these conditions (25). More notably, a significant decline in their function has been noted in older individuals and patients diagnosed with neurodegenerative disorders like Alzheimer's disease (26). Hip-NSCs, as all stem cells, have the ability to proliferate and differentiate into multiple lineages $(27,28)$. It has been demonstrated that the propensity of primary NSCs to differentiate into neurons and glial cells, measured by parameters including the differentiation rate and characteristics of neural cells generated, varies depending on the brain region that cells were isolated from; therefore, Hip-NSCs have regional specificity $(14,29)$.

In the present study, primary Hip-NSCs proliferated rapidly and aggregated into neurospheres with an orbicular morphology within $36 \mathrm{~h}$ of plating. In addition, during suspension culture, the passaged Hip-NSCs did not attach to the surface of the flask and exhibited the characteristics of primary Hip-NSCs. Following differentiation, cells organized themselves radially during the early stages, and in the initial three weeks exhibited a tendency to differentiate into astrocytes in the absence of exogenous cytokines. Studies have demonstrated that the yield of DA neurons from NSCs increased significantly in the presence of glial cell-derived neurotrophic factor (GDNF) and associated cytokines $(6,30,31)$. GDNF activates the expression of Nurr1 and pituitary homeobox 3 and has been used to create an in vitro PD model from NSCs. When overexpressed, GDNF is able to increase or improve the cognitive function of aging animals $(32,33)$. It has been reported that NSCs isolated from the embryonic midbrain have an increased tendency to differentiate into DA neurons compared with NSCs from alternative regions of the brain (34). This suggests that NSC differentiation and cell fate specification is influenced by their intrinsic properties, in addition to exogenous signaling molecules. A previous study investigated the molecular 
A

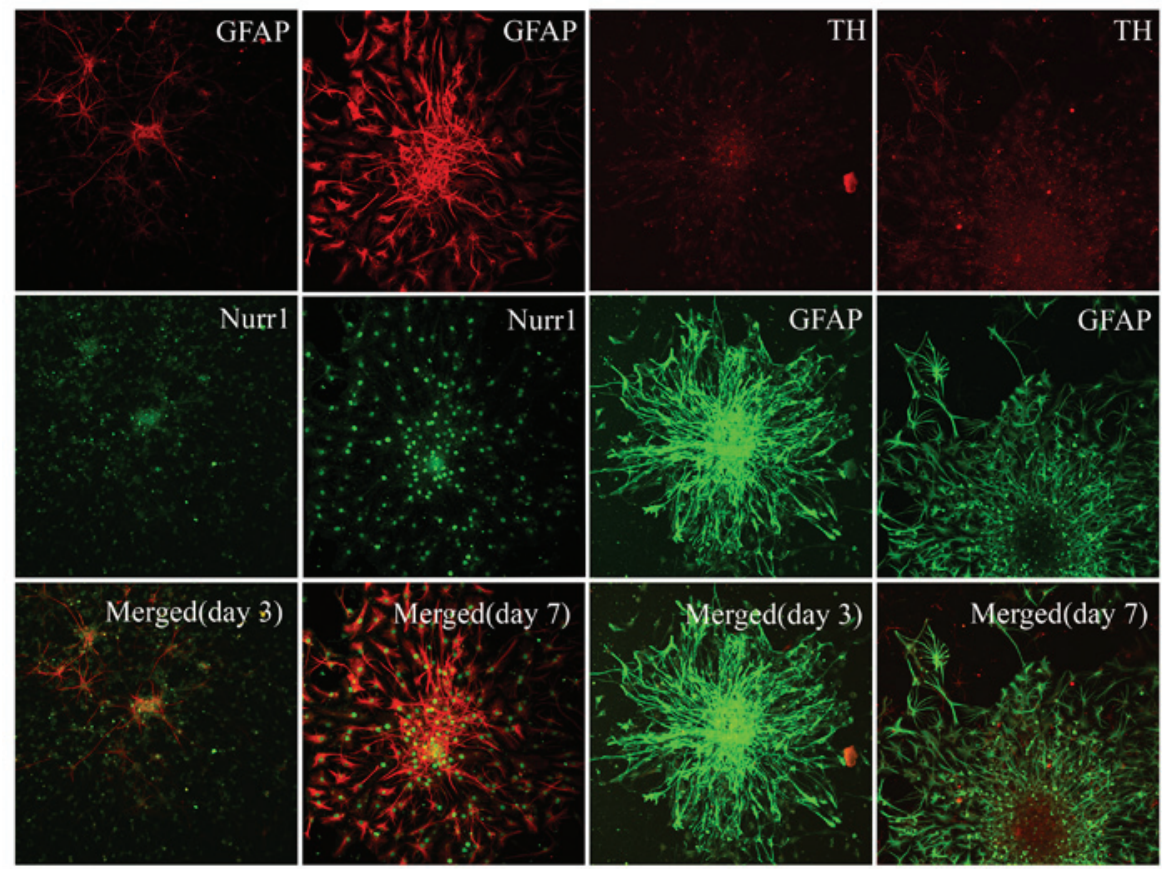

B

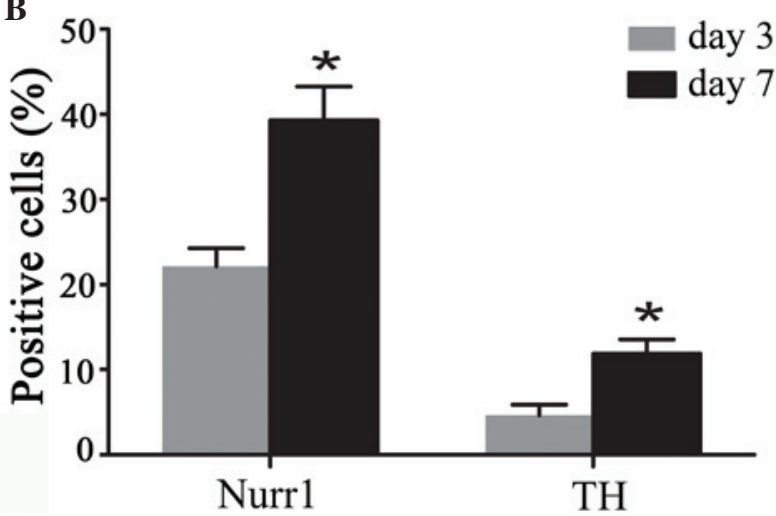

Figure 5. Immunohistochemical analysis of expression of Nurr1 and TH and GFAP at various stages of Hip-NSC differentiation. (A) Expression of GFAP (red) and Nurrl (green) and overlaid images at day 3 and 7; and expression of TH (red) and GFAP (green) and overlaid images at day 3 and 7 of differentiation. (B) Nurrl- and TH-positive differentiated Hip-NSCs increased significantly from day 3 (22.23 \pm 2.10 and $4.63 \pm 1.25 \%$, respectively) to day 7 (39.30 \pm 3.96 and $11.9 \pm 1.68 \%$, respectively). Analysis of variance was performed, followed by Dunnett's post hoc test. ${ }^{~} \mathrm{P}<0.05$, vs. day 3 . Magnification, x 200 . Nurr1, nuclear receptor related-1 protein; TH, tyrosine hydroxylas GFAP, glial fibrillary acidic protein; Hip-NSC, hippocampal neural stem cell.
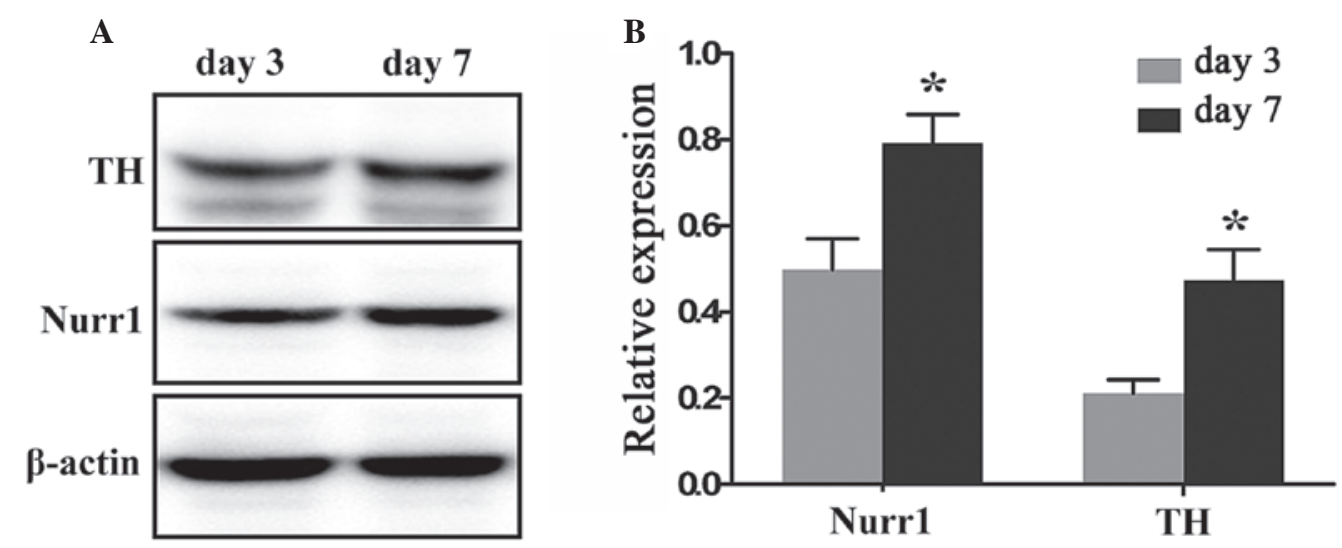

Figure 6. Analysis and quantification of Nurrl and TH protein expression levels at various stages of hippocampal neural stem cell differentiation. (A) Nurrl and TH protein bands detected by western blotting, at days 3 and 7 of differentiation. $\beta$-actin was used as an internal control. (B) The relative expression of Nurrl and TH protein was shown at day $3(0.499 \pm 0.072$ and $0.212 \pm 0.031$, respectively) and day $7(0.792 \pm 0.067$ and $0.473 \pm 0.072$, respectively). Densitometric quantification of Nurrl and TH protein expression, normalized to $\beta$-actin. "P<0.05 vs. day 3 , assessed by Student's $t$-test. Data are presented as the mean \pm standard error. Nurr1, nuclear receptor related-1 protein; TH, tyrosine hydroxylase. 
mechanism underlying the generation of DA neurons based on gene expression analysis and knockout studies identified various transcription factors that appear to be important in this process (35). A previous study confirmed Nurrl as an important factor regulating the differentiation of midbrain DA neurons, cell survival and acquisition of neuronal properties (36). In mice, Nurrl gene knockout resulted in a reduction in $\mathrm{TH}$ expression in ventral mesencephalon neurons and inhibited production of dopamine in the striatum. However, the levels of norepinephrine, serotonin and acetylcholine were not altered $(30,37)$. A previous study reported that Nurr1-induced differentiation of TH-positive cells from embryonic stem cells was not completely neuronogenic (38). Elevated expression of TH in differentiated glial cells was observed, indicating that Nurrl was not a specific inducer of midbrain DA neuronal fate, and that Nurr1 alone was not sufficient to induce NSCs to differentiate into mature DA neurons (39). Additional studies confirmed that expression of forkhead box protein A1/2, orthodenticle homeobox 2 , engrailed-1 and paired-like homeodomain 3 manipulated the development and differentiation of adult midbrain DA neurons (39-41).

In the current study, the differentiation of Hip-NSCs into Nurr1 and TH-positive neurons increased significantly with time under low serum conditions. Nurrl expression was detected during the early phase of differentiation and increased progressively. Therefore, Nurr1 may be indispensable for the generation of midbrain DA neurons from Hip-NSCs in vitro (31). The results of the present study suggest that the factors controlling in vitro differentiation of Hip-NSCs into specific neuronal fates include their intrinsic gene expression profile and their microenvironment. Furthermore, Hip-NSCs in adherent culture were demonstrated to generate not only neurons, but also glial cells expressing Nurrl, indicating that Nurrl expression is not specific to the development of midbrain DA neurons. Additional studies are required to identify alternative transcription factors that may act synergistically with Nurrl to induce a DA neuronal fate.

\section{Acknowledgements}

The present study was supported by grants from The National Science Foundation of China (grant nos., 81160169 and 81360062).

\section{References}

1. Yacoubian TA and Standaert DG: Targets for neuroprotection in Parkinson's disease. Biochim Biophys Acta 1792: 676-687, 2009.

2. Braak H, Bohl JR, Müller CM, Rüb U, de Vos RA and Del Tredici K: Stanley fahn lecture 2005: The staging procedure for the inclusion body pathology associated with sporadic Parkinson's disease reconsidered. Mov Disord 21: 2042-2051, 2006.

3. Diaz NL and Waters $\mathrm{CH}$ : Current strategies in the treatment of Parkinson's disease and a personized approach to management. Expert Rev Neurother 9: 1781-1789, 2009.

4. Reichmann H: New prospects for therapy in Parkinson's disease. Drug Res (Stuttg) 63 (Suppl 1): S23, 2013.

5. Ding YX, Wei LC, Wang YZ, Cao R, Wang X and Chen LW: Molecular manipulation targeting regulation of dopaminergic differentiation and proliferation of neural stem cells or pluripotent stem cells. CNS Neurol Disord Drug Targets 10: 517-528, 2011.
6. Lim MS, Chang MY, Kim SM, Yi SH, Suh-Kim H, Jung SJ, Kim MJ, Kim JH, Lee YS, Lee SY, et al: Generation of dopamine neurons from rodent fibroblasts through the expandable neural precursor cell stage. J Biol Chem 290: 17401-17414, 2015.

7. Gyárfás T, Knuuttila J, Lindholm P, Rantamäki T and Castrén E: Regulation of brain-derived neurotrophic factor (BDNF) and cerebral dopamine neurotrophic factor (CDNF) by anti-parkinsonian drug therapy in vivo. Cell Mol Neurobiol 30: 361-368, 2010.

8. Hauser DN and Cookson MR: Astrocytes in Parkinson's disease and DJ-1. J Neurochem 117: 357-358, 2011.

9. Wang YH, Yu HT, Pu XP and Du GH: Baicalein prevents 6-hydroxydopamine-induced mitochondrial dysfunction in SH-SY5Y cells via inhibition of mitochondrial oxidation and up-regulation of DJ-1 protein expression. Molecules 18: 14726-14738, 2013.

10. Okano H and Sawamoto K: Neural stem cells: Involvement in adult neurogenesis and CNS repair. Philos Trans R Soc Lond B Biol Sci 363: 2111-2122, 2008.

11. Muramatsu S, Okuno T, Suzuki Y, Nakayama T, Kakiuchi T, Takino N, Iida A, Ono F, Terao K, Inoue N, et al: Multitracer assessment of dopamine function after transplantation of embryonic stem cell-derived neural stem cells in a primate model of Parkinson's disease. Synapse 63: 541-548, 2009.

12. Williams CJ and Dexter DT: Neuroprotective and symptomatic effects of targeting group III mGlu receptors in neurodegenerative disease. J Neurochem 129: 4-20, 2014.

13. Richardson JR and Hossain MM: Microglial ion channels as potential targets for neuroprotection in Parkinson's disease. Neural Plast 2013: 587418, 2013.

14. Wei LC, Ding YX, Liu YH, Duan L, Bai Y, Shi M and Chen LW: Low-dose radiation stimulates Wnt/ $\beta$-catenin signaling, neural stem cell proliferation and neurogenesis of the mouse hippocampus in vitro and in vivo. Curr Alzheimer Res 9: 278-289, 2012.

15. Kishi Y, Takahashi J, Koyanagi M, Morizane A, Okamoto Y, Horiguchi S, Tashiro K, Honjo T, Fujii S and Hashimoto N: Estrogen promotes differentiation and survival of dopaminergic neurons derived from human neural stem cells. J Neurosci Res 79: 279-286, 2005.

16. Zuo FX, Bao XJ, Sun XC, Wu J, Bai QR, Chen G, Li XY, Zhou QY, Yang YF, Shen Q and Wang RZ. Transplantation of human neural stem cells in a Parkinsonian model exerts neuroprotection via regulation of the host microenvironment. Int J Mol Sci 16: 26473-26492, 2015.

17. Cave JW, Wang M and Baker H: Adult subventricular zone neural stem cells as a potential source of dopaminergic replacement neurons. Front Neurosci 8: 16, 2014.

18. Yamashita T and Abe K: Direct reprogrammed neuronal cells as a novel resource for cell transplantation therapy. Cell Transplant 23: 435-439, 2014.

19. Trueman RC, Klein A, Lindgren HS, Lelos MJ and Dunnett SB: Repair of the CNS using endogenous and transplanted neural stem cells. Curr Top Behav Neurosci 15: 357-398, 2013.

20. Buttery PC and Barker RA: Treating Parkinson's disease in the 21st century: Can stem cell transplantation compete? J Comp Neurol 522: 2802-2816, 2014.

21. Sadan O, Bahat-Stromza M, Barhum Y, Levy YS, Pisnevsky A, Peretz H, Ilan AB, Bulvik S, Shemesh N, Krepel D, et al: Protective effects of neurotrophic factor-secreting cells in a 6-OHDA rat model of Parkinson disease. Stem Cells Dev 18: 1179-1190, 2009.

22. Li F, Wang M, Zhu S, Li L, Xiong Y and Gao DS: The potential neuroprotection mechanism of GDNF in the 6-OHDA-induced cellular models of Parkinson's disease. Cell Mol Neurobiol 33: 907-919, 2013.

23. Ren X, Zhang T, Gong X, Hu G, Ding W and Wang X: AAV2-mediated striatum delivery of human CDNF prevents the deterioration of midbrain dopamine neurons in a 6-hydroxydopamine induced parkinsonian rat model. Exp Neurol 248: 148-156, 2013.

24. Ogawa I, Saito Y, Saigoh K, Hosoi Y, Mitsui Y, Noguchi N and Kusunoki S: The significance of oxidized DJ-1 protein (oxDJ-1) as a biomarker for Parkinson's disease. Brain Nerve 66: 471-477, 2014 (In Japanese).

25. Kahle PJ, Waak J and Gasser T: DJ-1 and prevention of oxidative stress in Parkinson's disease and other age-related disorders. Free Radic Biol Med 47: 1354-1361, 2009.

26. Hebsgaard JB, Nelander J, Sabelström H, Jönsson ME, Stott S and Parmar M: Dopamine neuron precursors within the developing human mesencephalon show radial glial characteristics. Glia 57: 1648-1658, 2009. 
27. Reynolds BA and Weiss S: Generation of neurons and astrocytes from isolated cells of the adult mammalian central nervous system. Science 255: 1707-1710. 1992.

28. Ding YX, Wei LC, Wang YZ, Cao R, Wang X and Chen LW: Molecular manipulation targeting regulation of dopaminergic differentiation and proliferation of neural stem cells or pluripotent stem cells. CNS Neurol Disord Drug Targets 10: 517-528, 2011.

29. Carrillo-García C, Suh Y, Obernier K, Hölzl-Wenig G, Mandl C and Ciccolini F: Multipotent precursors in the anterior and hippocampal subventricular zone display similar transcription factor signatures but their proliferation and maintenance are differentially regulated. Mol Cell Neurosci 44: 318-329, 2010.

30. Ambasudhan R, Dolatabadi N, Nutter A, Masliah E, Mckercher SR and Lipton SA: Potential for cell therapy in Parkinson's disease using genetically-programmed human embryonic stem cell-derived neural progenitor cells. J Comp Neurol 522: 2845-2856, 2014.

31. Park CH, Lim MS, Rhee YH, Yi SH, Kim BK, Shim JW, Kim YH, Jung SJ and Lee SH: In vitro generation of mature dopamine neurons by decreasing and delaying the expression of exogenous Nurr1. Development 139: 2447-2451, 2012.

32. Lei Z, Jiang Y, Li T, Zhu J and Zeng S: Signaling of glial cell line-derived neurotrophic factor and its receptor GFR $\alpha 1$ induce Nurr1 and Pitx3 to promote survival of grafted midbrain-derived neural stem cells in a rat model of Parkinson disease. J Neuropathol Exp Neurol 70: 736-747, 2011.

33. Alvarez-Castelao B, Losada F, Ahicart P and Castaño JG: The N-terminal region of Nurr1 (a.a 1-31) is essential for its efficient degradation by the ubiquitin proteasome pathway. PloS One 8: e55999, 2013.
34. Bang SY, Kwon SH, Yi SH, Yi SA, Park EK, Lee JC, Jang CG, You JS, Lee SH and Han JW: Epigenetic activation of the Foxa2 gene is required for maintaining the potential of neural precursor cells to differentiate into dopaminergic neurons after expansion. Stem Cells Dev 24: 520-533, 2015.

35. Moreno-Bravo JA, Martinez-Lopez JEand Puelles E: Mesencephalic neuronal populations: New insights on the ventral differentiation programs. Histol Histopathol 27: 1529-1538, 2012.

36. Barneda-Zahonero B, Servitja JM, Badiola N, Miñano-Molina AJ, Fadó R, Saura CA and Rodríguez-Alvarez J: Nurrl protein is required for N-methyl-D-aspartic acid (NMDA) receptor-mediated neuronal survival. J Biol Chem 287: 11351-11362, 2012.

37. Jiang C, Wan X, He Y, Pan T, Jankovic J and Le W: Age-dependent dopaminergic dysfunction in Nurrl knockout mice. Exp Neurol 191: $154-162,2005$.

38. Sonntag KC, Simantov R, Kim KS and Isacson O: Temporally induced Nurrl can induce a non-neuronal dopaminergic cell type in embryonic stem celt differentiation. Eur J Nearosci 19: 1141-1152, 2004.

39. Kittappa R, Chang WW, Awatramani RB and McKay RD: The foxa 2 gene controls the birth and spontaneous degenerate of dopamine neurons in old age. PLoS Biol 5: e325, 2007.

40. Veenvliet JV, Dos Santos MT, Kouwenhoven WM, von Oerthel L, Lim JL, van der Linden AJ, Koerkamp MJ, Holstege FC and Smidt MP: Specification of dopaminergic subsets involves interplay of En1 and Pitx3. Development 140: 3373-3384, 2013.

41. Panman L, Papathanou M, Laguna A, Oosterveen T, Volakakis N, Acampora D, Kurtsdotter I, Yoshitake T, Kehr J, Joodmardi E, et al: Sox6 and Otx2 control the specification of substantia nigra and ventral tegmental area dopamine neurons. Cell Rep 8: 1018-1025, 2014. 